\title{
VALOR PATRIMONIAL: USOS, ABUSOS E CONTEUDO INFORMACIONAL
}
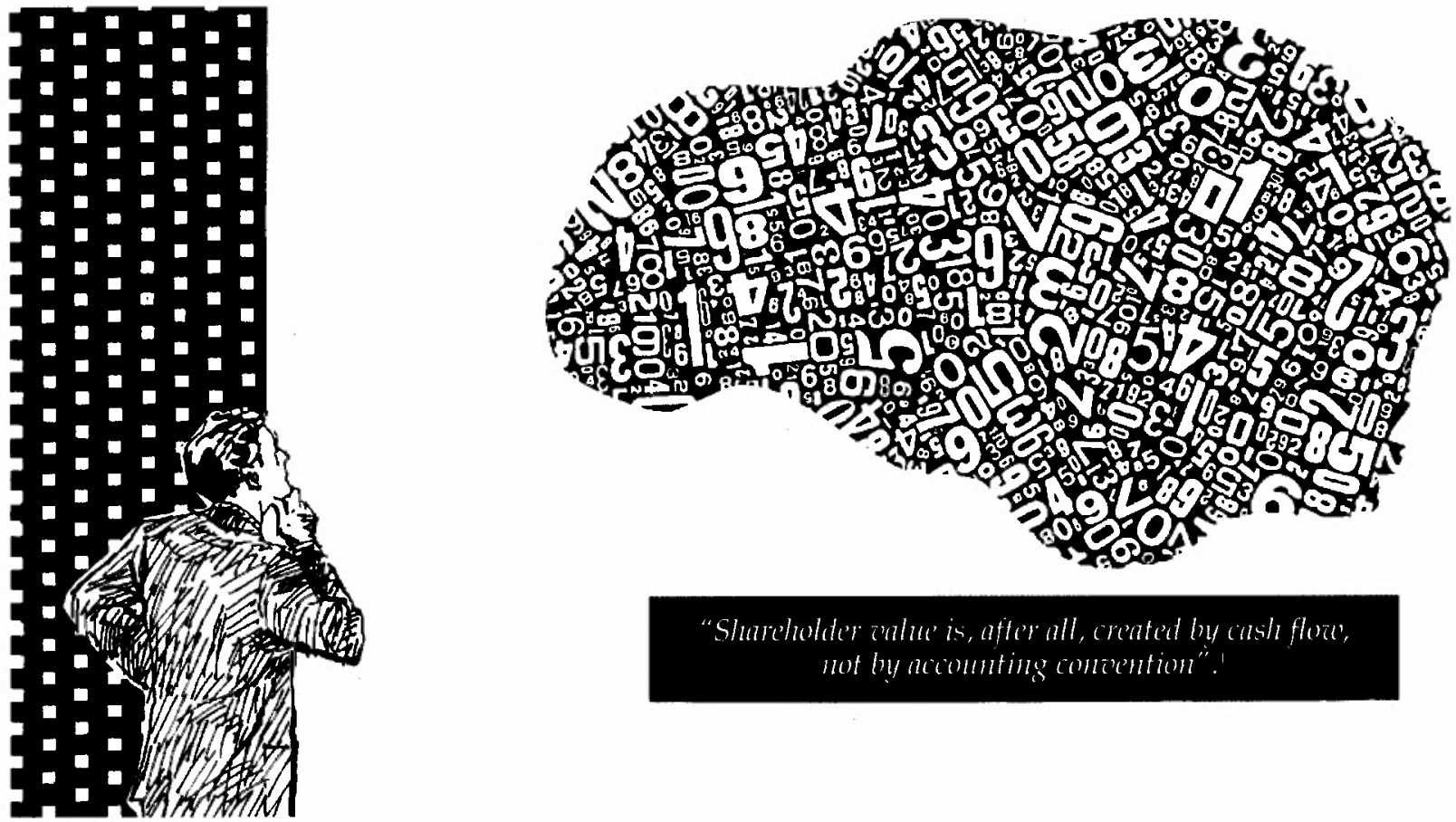

"Shureholder arahue is, affer all, created bu calsh flowe,

not by acounting comerention".

Helio de Paula Leite

Professor Assistente do Departamento de Contabilidade, Finanças e Controle da EAESP/FGV.

Antonio Zoratto Sanvicente

Professor Titular em Finanças da FEAVUSP.

* RESUMO: Por meio de um "event study", discutimos a utilização do valor patrimonial da ação no processo de avaliação de investimentos no mercado brasileiro de capitais. O valor patrimonial é analisado do ponto de vista da noção geralmente aceita de valor na teoria de Finanças, ou seja, valor presente de fluxos de caixa futuros, e depois é considerado nas situações em que é usado por analistas.

Testamos, a seguir, a significância do conteúdo informacional do valor patrimonial da ação através da mensuração das respostas dos preços de mercado à divulgação de novos valores patrimoniais.

Os resultados indicam que o valor patrimonial não possui conteúdo informacional significativo, e que há alguma antecipação ao evento por nós definido (entrega de demonstrações financeiras à Bolsa de Valores de São Paulo). Em vista do que propõe a moderna teoria de Finanças, este trabalho aponta para comportamento racional pelos participantes do mercado de açôes.
* PALAVRAS-CHAVES: Valor patrimonial da ação, conteúdo informacional, "capital asset pricing model" (CAPM), "event study", divulgação de dados contábeis $e$ financeiros.

* ABSTRACT: This paper discusses the use of book value per share in investment analysis in the Brazilian equities markets. The concept of book value per share is first discussed on the basis of the generally accepted notion of value in the modern theory of Finance, that is, present value of future cash flows, and we refer to some of its uses in the Brazilian context.

We then move on to test the significance of the information content of book value per share, by measuring the magnitude of market price reactions to news of changes in book value per share.

The results reported in this paper indicate a lack of significance in the information content of book value per share, an evidence of rational behavior by market participants. We perceived some antecipation by the market to the news of financial statement submission to the São Paulo Stock Exchange.

* KEY WORDS: Book value per share, information content, capital asset pricing model (CAPM), event study, accounting and financial disclosure.

1. RAPPAPORT, A. Creating Shareholder Value. New York, The Free Press, 1986, p. 44. 


\section{INTRODUÇÃO}

$\mathrm{H}$

á décadas, o mundo acadêmico de Teoria de Finanças se debate em torno da questão do valor intrínseco, ou preço justo, das empresas em operação. A mesma intrigante questão pode ser enfocada através da determinação do preço justo das ações negociadas nas Bolsas de Valores. Dezenas de artigos e livros são escritos todos os anos sobre esse tema central e, quanto mais avançamos teoricamente, mais e mais perguntas vão brotando em nosso espírito e, cada vez mais, nos distanciamos de uma solução simples e singela como aquela que tenta identificar o valor patrimonial contábil de uma empresa com o seu valor de mercado. Apesar disso, entretanto, a utilização do valor patrimonial contábil como aproximação do valor de mercado de empreendimentos e ações negociadas no Mercado Secundário segue tendo uma popularidade notável.

Com efeito a nossa legislação societária em várias situações consagra o valor patrimonial contábil como parâmetro determinante do valor "justo" de mercado das ações. O artigo 170 da Lei 6404 de 15/12/76, que trata da fixação do preço de emissão das ações, e o seu artigo 45 , que trata do reembolso dos acionistas dissidentes de deliberação da assembléia geral (direito de recesso) são exemplos claros dessa tendência. Várias tentativas de privatização de empresas estatais esbarraram com esse parâmetro no passado recente. Por outro lado, é freqüente na imprensa nacional a divulgação de quadros apontando para existência de verdadeiras "barganhas" no mercado das Bolsas representadas por ações cujos valores de mercado estão muito abaixo dos respectivos valores patrimoniais contábeis. Também na imprensa internacional não é raro se encontrar esse tipo de comparação.

O nosso artigo tem por objetivo aprofundar o debate em torno dessa prática de avaliação de empreendimentos e de suas ações. Ele está estruturado nas seguintes partes: discussão do conteúdo informacional do valor patrimonial contábil no contexto da avaliação empresarial, especificação da hipótese nula do teste que realizamos (ou seja, o valor patrimonial contábil não tem conteúdo informacional no âmbito da avaliação empresarial), descrição da metodologia do teste realizado (event study), resultados da pesquisa, conclusões e bibliografia sobre o assunto em pauta. Desejamos expressar nossos sinceros agradecimentos ao Instituto Brasileiro de Mercado de Capitais - IBMEC - que colocou a nossa inteira disposição o seu banco de dados relativo a demonstrativos contábeis de todas as empresas negociadas em Bolsa, facilitando sobremaneira a nossa tarefa.

\section{O CONTEÚDO INFORMAGIONAL DO VALOR PATRIMONIAL}

Hopp \& Paula Leite ${ }^{2}$ já tiveram a oportunidade de chamar a atenção para o fato de que "a liturgia da contabilidade sempre produziu, aos menos avisados, uma falsa sensação de segurança e conforto. A elegância algébrica do perfeito empate entre os totais do ativo e passivo, a disposição colunar e detalhada do demonstrativo de resultados, os nomes sofisticados com que as contas são batizadas, o cálculo do 'lucro real' livre de distorções inflacionárias, o certificado de auditoria e outros detalhes graficos dos relatórios contábeis sempre emprestaram a eles uma aura de exatidão e conservadorismo, algo que, mesmo sem compreendermos inteiramente, podemos confiar com satisfatória segurança". Provavelmente, o balanço patrimonial seja a peça contábil de maior poder de impacto psicológico sobre o investidor menos avisado. Como deixar de confiar num relatório tão exato e tão detalhado, assinado pelo contador e diretores da empresa e aprovado por seus auditores "dentro dos princípios contábeis geralmente aceitos"? Entretanto, o balanço patrimonial é o último relatório contábil da empresa emissora a ser consultado por alguém realmente interessado em determinar o preço justo de uma ação. Ali há muito pouca coisa importante para ser aproveitada por quem se disponha a realizar o tedioso exercício da avaliação de ações. Tampouco pode haver correlação confiável entre o patrimônio líquido contábil - centro do balanço patrimonial - e o valor de mercado da empresa.

Sob muitos aspectos, os processos de avaliação de árvores e empresas guardam semelhanças notáveis. Se alguém deseja comprar uma árvore frutífera, certamente ajustará seu preço de oferta à produção futura de frutos dessa árvore que for possível antecipar no momento da aquisição. Assim, o comprador procurará fazer uma estatística sobre a produção dessa árvore no passado recente, observar cuidadosamente o seu estado atual, avaliar corretamente a vida útil que ainda lhe resta e tentar inferir, diante dessas e de outras informações sobre o clima da região, qualidade do solo e outras variáveis ambientais que direta ou indiretamente afetam a vida da árvore, qual a produção provável de frutos que ela será capaz de render no futuro. O valor máximo que o comprador estará disposto a desembolsar pela árvore depende diretamente do provável fluxo de sua produção futura e inversamente da taxa de retorno que for razoável se esperar para investimentos agrícolas cujas produções estejam sujeitas a riscos semelhantes. 
A não ser que o comprador pretenda comprar lenha para a sua lareira, o valor da árvore em si é desprezível: na verdade, ele não está comprando uma árvore, ele está adquirindo uma produção futura de frutos por ele mesmo estimada.

O mesmo ocorre com a aquisição de empresas. Aliás, não é outra a metodologia corrente no mercado de compra e venda de bares e padarias: é curioso observar que, nesse mercado muito ativo e de razoável liquidez, o valor contábil do patrimônio líquido nunca entra na cogitação de compradores e vendedores. Tradicionalmente, o preço do negócio é estabelecido por um múltiplo (que geralmente gira em torno de nove a doze) de seu faturamento mensal. Antecipando-se às modernas teorias do valor que elegem o fluxo de caixa como parâmetro central do processo de avaliação, os empresários desse setor já consagraram um método prático e objetivo para estabelecer o preço de suas empresas: comprador potencial $\mathbf{e}$ vendedor permanecem juntos durante um mês diante da caixa registradora, conferindo o volume do seu fluxo até que se tenha uma idéia precisa desse parâmetro central, para, então, concluirem a transação, a qual, usualmente, não envolve a transferência das dívidas.

O balanço patrimonial é uma peça contábil extremamente frágil para os propósitos da análise e diagnóstico financeiros. Desde as primeiras aulas de Contabilidade Introdutória, estamos informados de que o balanço patrimonial de uma empresa se altera (às vezes drasticamente) a cada transação registrada. Tomar o último balanço patrimonial publicado e sobre ele apoiar nossa análise é, no mínimo, uma atitude ingênua, porque ele reflete a situação financeira do empreendimento em determinado momento (não necessariamente o mais representativo da trajetória real da empresa). Por isso mesmo, a análise de tendência é a única que pode aproveitar as informações do balanço patrimonial, observando-se uma série de demonstrativos consecutivos ao longo de um período suficientemente extenso para a localização de tendências. Não se pode formar julgamentos razoáveis pela leitura de um ou dois balanços patrimoniais; é preciso dispor de uma série deles para chegar a diagnósticos consistentes. Além disso, deve-se ressaltar o papel importante de informações não contábeis no processo de avaliação de empresas (cenários econômicos, análise setorial, previsão da demanda por produtos da empresa etc.).

Quando alguém pretende adquirir uma determinada ação - como no caso da ár- vore - o ponto importante é a previsão do fluxo de renda que a ação poderá produzir no futuro. Nesse sentido, a variável estratégica é a operação que a empresa tem condições de conduzir, desenvolver e ampliar. O núcleo gerador de rendimentos ao acionista é a operação desenvolvida pela empresa emissora e não o valor contábil líquido de seus ativos.

Os aspectos liquidez e endividamento, normalmente analisados através do balanço patrimonial, são secundários no processo de avaliação. De nada adianta a empresa desfrutar de alta liquidez e endividamento reduzido se a operação que ela desenvolve estiver "em pane". Da mesma forma, liquidez e endividamentos críticos podem não ser uma desvantagem insuperável, caso a empresa administre uma operação rentável e promissora em termos de geração de recursos no futuro. Como se vê, o balanço patrimonial é instantâneo demais para fundamentar uma análise da profundidade requerida pela avaliação empresarial. $O$ imediatismo subjacente à análise isolada do último balanço patrimonial é um péssimo conselheiro do analista. É fundamental que se adote como orientação principal a antecipação do futuro no mais amplo horizonte temporal que for possível, antes de arriscarmos uma opinião sobre o valor "justo" de um empreendimento. É o longo prazo, e não o presente, que nos pode fornecer guias mais seguros para antecipar resultados empresariais. Índices financeiros pobres são efeito e não causa de operações malsucedidas. Por outro lado, índices financeiros pobres podem ser o reflexo de um momento crítico da vida de um excelente projeto de investimento em andamento.

Um breve levantamento bibliográfico pode fornecer-nos o ponto de vista de autores clássicos sobre o assunto.

Em Security Analysis - Principles and Technique (a "bíblia" da análise fundamentalista de ações), Graham, Dodd \& Cottle ${ }^{3}$ assim se posicionam em relação ao valor patrimonial das ações:

"Há uma boa razão para não se levar em consideração o valor (contábil) dos ativos como fator determinante. O preço médio de mercado de uma ação ordinária ao longo dos anos depende essencialmente do 'earning power' $e$ do pagamento de dividendos. Esses fatores, por outro lado, normalmente não mantêm nenhuma relação íntima ou razoavelmente consistente com o valor dos ativos. Investidores e especuladores têm descoberto que o valor (contábil) dos ativos, tipicamente, não constitui um guia para o 'earning power value' ou preço médio de mercado. Por isso, eles gradualmente passaram a não dar praticamente nenhum peso a este fator".
3. GRAHAM, B.; DODD, D. L. \& COTTLE, S. Security Analysis Principles and Technique. 4a. ed. International Student Edition, New YorkTokio, McGrawHill Book Co. \& Kogakusha Co. Ltda., 1962, p. 217. 
4. FRANCIS, J. C. Investments: Analysis and Management. 4a.ed. New York, McGraw-Hill Book Co., 1986, p. 31.

5. SHARPE, W. F. Investments. 3a. ed. Englewood Cliffs, N.J., Prentice Hall, 1985, p.446.

6. COPELAND, T. E. \& WESTON, J. F. Financial Theory and Corporate Policy. 3a. ed. Reading Mass., Addison-Wesley Publishing Co., 1988, p. 447.

7. BRIGHAM, E. F. Financial Management: Theory and Practice. 3a. ed. Tokio, Holt-Saunders International Editions, 1982, p.216.

8. COPELAND, T. E. \& WESTON, J. F. Op. cit., p. 607

9. BREALEY, R. A. \& MYERS, S. C Principles of Corporate Finance. 2a. ed. New York, N.Y., McGraw-Hill Book Co., 1984, p. 783.

10. SANVICENTE, A. Z. \& MELLAGI FILHO, A. Metodologia de Estimação do Desvio-Padrão Implícito nos Preços de Mercado de Opções: Uma Aplicação à Alta de Cotações Quando do Anúncio do Plano Cruzado (março de 1986). Monografia premiada no $1^{\circ}$. Concurso de Monografias sobre Mercado de Capitais, S.A. Moinho Santista Indústrias Gerais e ABAMECSP, São Paulo, 1987, p. 10.

11. Ver SHARPE, W. F. "Capital Asset Prices: A Theory of Market Equilibrium - under Conditions of Risk". Journal of Finance, setembro, 1964, pp. 425-442; LINTNER, J. "The Valuation of Risk Assets and the Selection of Risky Investments in Stock Porttolio and Capital Budgets". Review of Economics and Statistics, fevereiro, 1965 , pp.13-37; MOSSIN, J. "Equilibrium in a Capital Asset Market". Econometrica, outubro, 1966, pp.768-783.
Francis ${ }^{4}$ declara que:

"O valor patrimonial e o valor de mercado provavelmente serão iguais quando a ação for emitida, mas, depois disto, parece que só por coincidência esses valores serão iguais em dado momento".

Por outro lado, Sharpe ${ }^{5}$ considera que se os relatórios preparados pelos contadores nos reportassem o resultado econômico (e não contábil) dos empreendimentos, o processo de "avaliação seria simples, uma vez que o contador ja teria realizado a tarefa. $O$ valor econômico de uma ação seria seu valor patrimonial e não haveria razão para se considerar o lucro em si. É necessária pouca evidência para demonstrar que os investidores geralmente consideram que as ações valem muito mais ou menos do que os valores patrimoniais reportados". Copeland \& Weston ${ }^{6}$ são taxativos ao afirmar que "não há qualquer. relacionamento entre os conceitos de valor patrimonial (por exemplo, lucros retidos) e o valor econômico do patrimônio". Brigham ${ }^{7}$ desaconselha a assumir que valor patrimonial e preço de mercado tendam a se igualar:

"O quociente entre o preço de mercado de uma ação e seu valor patrimonial é mais uma indicação de como os investidores encaram a empresa. Empresas com elevadas taxas de retorno sobre o capital próprio normalmente são negociadas a múltiplos muito maiores do valor patrimonial da ação do que as empresas com taxas de retorno mais baixas... O grau de conservadorismo adotado pelos contadores da empresa também pode afetar o indice 'preço de mercado/valor patrimonial'. Quanto mais conservadores forem os contadores, mais alto será o indice, ceteris paribus. O mesmo vale para o indice preço/lucro... A empresa típica do setor de transporte ferroviário, cuja taxa de retorno sobre o ativo é muito baixa, tem índice 'preço de mercado/valor patrimonial' inferior a 0,5. Empresas muito bemsucedidas, tais como IBM, alcançam taxas de retorno bastante elevadas e têm valor de mercado que é quatro ou cinco vezes maior do que seus valores patrimoniais". Parece claro que valor se relaciona com a renda futura e não com o custo histórico dos ativos da empresa, ao contrário do que afirma a sabedoria convencional.

Copeland \& Weston ${ }^{8}$ consideram que "os investidores extraem pouco benefício dos dados contábeis históricos porque eles não contêm nenhuma informação nova. Portanto, embora o relatório contábil anual possa servir como instrumento útil no monitoramento do desempenho da administração, ele tem pouco valor para a comunidade de investimentos. Dados verdadeiramente relevantes se referem ao futuro". Além disso, não se pode desconsiderar o fato que os relatórios contábeis estão sujeitos a regras e convenções que são essencialmente arbitrárias, o que reduz sensivelmente o conteúdo informacional desses relatórios para os propósitos da avaliação empresarial.

\section{FATORES DETERMINANTES DO VALOR}

Considerada uma das "cinco principais idéias em Finanças" por Brealey \& Myers", a associação entre o valor de um ativo e o valor presente líquido dos futuros fluxos de caixa que dele resultam significa que, ao ser aplicada às ações de uma empresa, pode-se descartar o papel de qualquer decisão passada e irreversível, o mesmo valendo para os fluxos de caixa já ocorridos. Pois são exatamente essas decisões e esses fluxos passados que estão refletidos no cálculo do valor patrimonial. Podemos escrever, conforme Sanvicente \& Mellagi Filho ${ }^{10}$, que o valor de uma ação é dado por:

$$
\text { Valor da ação }=\sum_{t=1}^{\infty} \frac{E\left(D_{t}\right)}{\left\{1+R_{f}+\beta\left[E\left(R_{m}\right)-R_{f}\right]\right]^{t}}
$$

onde: $\mathrm{E}\left(\mathrm{D}_{\mathbf{t}}\right)$

representa a série de dividendos esperados para o futuro;

$\mathbf{R}_{\mathrm{f}} \quad$ representa a remuneração de uma aplicação sem risco, por período;

$$
\begin{array}{cl}
\beta\left[E\left(R_{m}\right)-R_{f}\right] & \begin{array}{l}
\text { representa o prêmio pelo } \\
\text { risco sistemático da ação que } \\
\text { está sendo avaliada } \\
\text { ( } \beta \text { é o coeficiente de risco } \\
\text { sistemático dessa ação), e }
\end{array} \\
E\left(R_{m}\right)-R_{f} & \begin{array}{l}
\text { é o prêmio que o mercado } \\
\text { oferece por unidade de } \\
\text { risco sistemático. }
\end{array}
\end{array}
$$

O cálculo proposto na equação (1) nada mais representa do que a determinação do valor presente líquido da aplicação em ações de uma empresa, a uma taxa de desconto ajustada pelo risco sistemático (não diversificável) da ação, conforme o Capital Asset Pricing Model - CAPM de Sharpe, Lintner, \& Mossin".

Portanto, aplica-se também a esse caso a metodologia já consagrada de avaliação de uma alternativa de investimento baseada em "fluxos de caixa descontados". Já que é assim, a lógica e a coerência também determinam que um dos princípios básicos dessa metodologia seja obedecido: ignorar fluxos de caixa ocorridos até o momento da decisão de investimento que esteja sendo analisada. E o "valor patrimonial" nada mais é do que o reflexo contábil tão somente de decisões passadas.

Apesar da virtual unanimidade entre os autores clássicos de Teoria de Finanças com 
respeito à falta de consistência da comparação entre preços de mercado e valores patrimoniais das ações, ela continua sendo uma das mais populares "regras práticas" aplicadas pelos investidores e profissionais do mercado, tanto aqui quanto nos Estados Unidos. A Business Week de 21 de março de 1988 (p.52) traz um interessante quadro onde são comparados os preços correntes de algumas ações do mercado de balcão, em 4 de março de 1988 , com os respectivos valores patrimoniais, ao final do terceiro trimestre de 1987 . Um segundo índice (um tanto exótico) é também comparado com o preço de mercado nesse quadro: trata-se do "caixa líquido por ação" que corresponde à divisão do disponível menos o total das obrigações pelo número de ações emitidas. No levantamento dessa conceituada revista, 42 "barganhas" são selecionadas, demonstrando que elas estavam sendo negociadas no mercado secundário por um valor menor do que elas representavam em termos de "caixa por ação", ou seja, o que sobraria no caixa da empresa para cada ação emitida, após o pagamento de todas as suas dívidas sem a realização de qualquer ativo (circulante, realizável a longo prazo ou permanente).

A imprensa especializada nacional também com freqüência divulga quadros comparativos entre cotações $\mathrm{e}$ valores patrimoniais das ações negociadas em Bolsa. Como aqui há o problema da inflação, o valor patrimonial apurado pelo último balanço (31 de dezembro, por exemplo) é convenientemente corrigido (pela BTN) para a data em que o preço de mercado foi considerado para a comparação. A hipótese subjacente a esse procedimento é que, entre a data do balanço e a data da cotação, a empresa teve resultado nulo, um pressuposto ingênuo e que serve para demonstrar que a imaginação simplificadora não conhece limites. A comparação entre cotações e valor patrimonial, se fosse útil e consistente, não seria viável em termos práticos porque as empresas não são obrigadas (ainda) a levantar balanços patrimoniais a cada dia.

Tampouco devemos ficar impressionados diante da evidência de haver ações cujas cotações estão abaixo do respectivo "caixa por ação". Todos sabem ser o disponível o último ativo a ser considerado como alternativa de investimento por administradores criativos. Apenas eventualmente, a empresa deveria canalizar seus escassos recursos para o Open Market, geralmente, para aproveitar uma disponibilidade transitória; jamais deveriam ser essas aplicações o núcleo gerador dos rendimentos para o acionista. Afinal, por que criar uma estrutura empresarial entre $o$ acionista e o mercado de renda fixa se ele pode ter acesso direto a esse tipo de aplicação? Na verdade, um persistente excesso de disponibilidades é, antes de mais nada, um inequívoco sinal de que a empresa está em retrocesso e o máximo que se consegue fazer é canalizar os escassos fundos por ela administrados para a comodidade do prosaico mercado de renda fixa, longe dos riscos da aventura empresarial. Como poderíamos atribuir valor a uma ação cuja empresa está conseguindo fazer pelo acionista apenas o que ele pode fazer diretamente no mercado financeiro? ${ }^{12}$

Certamente, a popularidade do valor patrimonial decorre principalmente da simplicidade de seu cálculo. Há duas décadas, quando o mercado brasileiro de ações se concretizava como opção de investimento e alternativa de capitalização das empresas, havia uma reação generalizada às técnicas mais sofisticadas de avaliação de ações. Qualquer modelo que sugerisse a utilização do desviopadrão como medida de risco era instantaneamente rotulado de "teórico" ou "acadêmico". Naquela época, não havia no mercado máquinas de calcular eletrônicas e esses cálculos tediosos e demorados eram o passatempo apenas de professores de tempo integral. Até o final dos anos 60 , a régua de cálculo consistia no mais sofisticado engenho portátil para a realização de cálculos e sua precisão era insatisfatória. Tabelas financeiras e tábuas de logaritmos eram acessórios incômodos e indispensáveis para os executivos financeiros e analistas do mercado de ações. $O$ advento das máquinas portáteis e eletrônicas revolucionou esse cenário medieval. Os computadores de uso pessoal terminaram definitivamente com a desculpa da lentidão do processamento dos cálculos.

Nos últimos vinte anos, assistimos a uma verdadeira revolução no mercado de calculadoras financeiras e estatísticas e de microcomputadores. Equipamentos rápidos e com os programas necessários já embutidos estão disponíveis a preços acessíveis e não pode haver mais desculpas para evitarmos a aplicação dos modelos mais avançados de avaliação por causa da complexidade dos cálculos envolvidos. Enquanto o nosso mercado de ações se sofistica na área operacional, aproveitando os avanços da informática, não se percebe um desenvolvimento proporcional na disseminação dos conhecimentos e modelos disponíveis na área da análise de ações. Nossos alunos ainda continuam a perguntar, ao final de uma exposição sobre seleção de carteiras ótimas (diversificação de Markowitz), se essas teorias já foram alguma vez apli-
12. Conforme BREALEY, R. A \& MYERS, S. C., op. cit., cap. 13 , que se referem à do-it-yourself alternative. 
cadas... O índice "beta" ainda está cercado por uma mística típica da magia negra... "Será que ele funciona também no Brasil?", perguntam eles.

Vale a pena tentarmos medir a utilidade do valor patrimonial como indicador do valor das ações negociadas nas Bolsas de Valores brasileiras. Esse é o objetivo das próximas seções deste artigo.

\section{HIPÓTESE NULA DO TRABALHO}

\section{Conteúdo informacional}

A ocorrência de um evento envolvendo as ações de uma empresa terá "conteúdo informacional", ou "valor" como informação se nos disser algo que ainda não sabemos. Além disso, conforme Copeland \& Weston ${ }^{13}$, esse valor, representado por um ganho de utilidade, precisa ser calculado após a dedução dos custos de operação (ou transação, tais como corretagens e impostos), bem como os custos de obtenção da própria informação (por exemplo, despesas com a coleta de dados e os serviços de análise).

\section{Análise de resíduos e conteúdo informa- cional}

Conforme Griffin \& Sanvicente ${ }^{14}$, em seu trabalho sobre a reação de preços de ações à reclassificação do risco de crédito de debêntures de empresas americanas, uma das maneiras de projetar o experimento para análise do efeito de algum evento envolve, inicialmente, a especificação das hipóteses nula e alternativa a respeito de resíduos:

$$
\begin{aligned}
& \mathrm{H}_{\mathrm{O}}: \mathrm{E}\left(\tilde{\varepsilon}_{\mathrm{jt}} \mid \tilde{\theta}_{\mathrm{jt}}\right)-\mathrm{E}\left(\tilde{\varepsilon}_{\mathrm{jt}}\right)=0 \\
& \mathrm{H}_{\mathrm{A}}: \mathrm{E}\left(\tilde{\boldsymbol{\varepsilon}}_{\mathrm{jt}} \mid \tilde{\theta}_{\mathrm{jt}}\right)-\mathrm{E}\left(\tilde{\boldsymbol{\varepsilon}}_{\mathrm{jt}}\right) \neq 0 \\
& \text { onde: } \tilde{\varepsilon}_{\mathrm{jt}}=\text { resíduo (ou retorno extraordiná- }
\end{aligned}
$$

13. COPELAND, T. E \& WESTON, J. F. Op. cit., cap. 10

14. GRIFFIN, P. A. \& SANVICENTE A. Z. "Common Stock Returns and Rating Changes: A Methodological Comparison". Journal of Finance, março, 1982, pp. 103-119.

15. COPELAND, T. E. \& WESTON, J. F. Op. cit., pp. 361-362.

16. FOSTER, G. Financial Statement Analysis. Englewood Cliffs, N.J., Prentice Hall, 1986, pp.403-405. cutido neste trabalho, a simples ocorrência do evento "divulgação de um novo valor patrimonial".

Portanto, a hipótese nula indicaria a inexistência de "conteúdo informacional", pois corresponde a retorno extraordinário igual, com e sem informação. A rejeição da hipótese nula é que nos levaria a supor que o evento possa ter um impacto significativo.

Como é indicado por Copeland \& Weston ${ }^{15}$, em seus comentários sobre três alternativas básicas de cálculo de resíduos, o uso do CAPM pressupõe, em comparação com o "modelo de mercado", que o intercepto da relação linear entre o retorno e risco seja a taxa de retorno do ativo sem risco, $R_{\mathrm{ft}}$. Das três alternativas de cálculo de resíduos, é a única baseada numa especificação teórica para a formação de preços e retorno no mercado. Um exemplo bastante detalhado de cálculo de resíduos usando o CAPM para a determinação do retorno "normal" é apresentado por Foster ${ }^{16}$.

\section{Cálculo de resíduos acumulados}

A partir dos resíduos calculados para cada data desde 30 pregões anteriores até 5 pregões posteriores ao evento, também podemos medir resíduos acumulados até qualquer data de interesse, ou qualquer trecho de todo esse intervalo. O objetivo, nesse caso, é o de medir mais claramente a existência de movimentos sistemáticos dos preços: por exemplo, para determinar se há alguma antecipação, pelo mercado, da informação que seria transmitida quando da entrega das demonstrações financeiras à Bolsa de Valores. Essa antecipação tanto poderia ocorrer caso houvesse outro veículo para divulgação da informação (por exemplo, reuniões da empresa com analistas), quanto por meio de "vazamentos".

Isso foi feito para a "carteira", ou seja, o conjunto das empresas da amostra.

Além disso, porém, analisamos uma crosssection dos resíduos acumulados como reação de mercado a diversas variáveis, e não apenas à variação do valor patrimonial.

Como uma hipótese alternativa possível, poderíamos imaginar que, quanto maior a variação positiva do valor patrimonial, maior o resíduo acumulado entre duas datas quaisquer.

Porém, como a entrega das demonstrações financeiras implica em divulgação de outros dados (variação do lucro por ação, crescimento do faturamento, alterações de endividamento e risco financeiro), qualquer resíduo acumulado substancial poderia estar sendo causado por notícias a respeito de outra variável que é observada simultaneamente à 
variação do valor patrimonial. Além disso, a inclusão de dados sobre outras variáveis permite medir o "conteúdo informacional marginal" do valor patrimonial.

Assim, essa análise de cross-section fez uso de modelos de análise de regressão linear múltipla, nos quais os resíduos acumulados são a variável dependente, e variações de vaIor patrimonial, lucro por ação, faturamento e outros indicadores aparecem como variáveis explicativas. Esse tipo de enfoque é exposto em Foster ${ }^{17}$

\section{METODOLOGIA}

\section{Event study}

Num estudo como este, fazemos o que a literatura de Finanças tem chamado de event study. Como desejamos saber se o evento "divulgação do valor patrimonial" causa impacto significativo nos preços das ações, obedecemos, como é usual, ao seguinte procedimento:

a) uma vez definido o evento, levantamos a data cronológica de ocorrência para cada empresa ou ativo componente da amostra. Nesse caso, a data seguinte à do Boletim Diário de Informações que registra a entrega de demonstrações financeiras por uma empresa à Bolsa de Valores de São Paulo;

b) coletamos séries de taxas de retorno de cada ativo para algum número de períodos ou datas em torno da data do evento (por exemplo, desde 30 pregões antes até 5 pregões após o evento);

c) centralizamos as séries em torno da data zero (data do evento);

d) transformamos as séries de retornos em séries de resíduos, ou retornos extraordinários, subtraindo, para cada ação, e a cada data, o retorno "normal", como foi indicado anteriormente;

e) construímos uma série de médias desses resíduos, ao somar as séries de todas as empresas da amostra, e dividindo pelo número de empresas, como se os ativos compusessem uma carteira com pesos iguais. Também é calculado o desvio-padrão dessa série;

f) testamos a significância dessas médias, em algumas datas de interesse, usando a estatística " $\mathrm{t}$ " de Student, tal como em qualquer teste de hipóteses sobre média ou diferença de médias ${ }^{18}$.

Com essas mesmas linhas gerais, tal tipo de estudo teve seu início nos Estados Unidos com o clássico Ball \& Brown ${ }^{19}$, a respeito do conteúdo informacional da publicação de relatórios anuais das empresas, como no presente trabalho, com a diferença de que esses autores estavam mais preocupados com 0 conteúdo informacional de variações do lucro por ação. Outro estudo clássico, que utilizou a mesma metodologia, é o de Fama, Fischer, Jensen \& Roll ${ }^{20}$, sobre stock splits.

\section{Detalhes do estudo}

\section{a) Definição do evento}

No Brasil, as empresas abertas são obrigadas a apresentar demonstrações financeiras: a) à Comissão de Valores Mobiliários, através dos Informes apropriados; $b$ ) às Bolsas de Valores em que suas ações são negociadas; e c) ao público em geral, através de sua publicação em jornais de grande circulação. Além disso, pode haver divulgação em reuniões com analistas de valores mobiliários e entrevistas à imprensa ou noticiário sobre as empresas nos órgãos especializados ou não.

Mas, como não há padrão reconhecido pelo mercado quanto ao primeiro momento em que uma empresa divulga suas demonstrações financeiras, no todo ou em parte, para que haja processamento significativo das informações e sejam tomadas decisões de alteração de carteiras em conseqüência das conclusões assim formuladas, optamos por definir o evento sob estudo como sendo a entrega de demonstrações financeiras à Bolsa de Valores de São Paulo.

Todos os participantes mais ativos do mercado acompanham diariamente a evolução dos negócios através do Boletim Diário de Informaçōes (BDI), que regularmente informa quais as demonstrações financeiras entregues à Bolsa. Como o BDI chega às mãos desse público mais influente no início do dia seguinte, escolhemos, portanto, como data do evento, ou "data zero", o dia posterior ao da data do BDI que informa a entrega de demonstrações financeiras de alguma empresa.

b) Problemas de coleta de dados

Para que este estudo fosse feito, foi necessário coletar dados dos seguintes tipos:

1. datas de entrega de demonstrações financeiras;

2. séries de lucratividades mensais e diárias dos ativos incluídos na amostra;

3. demonstrações financeiras razoavelmente detalhadas de todas as empresas analisadas;

4. séries de taxas diárias de juros para representar o retorno de um ativo sem risco.

Essa coleta de dados tão elementares não está isenta de alguns problemas.

Nem sempre o BDI registra a entrega de demonstrações financeiras, seja por omissão,
17. Idem, ibidem, pp. 399-402.

18. Ver PYNDICK, R. S. \& RUBINFELD, D. L. Econometric Models and Economic Forecasts. 2a. ed. New York N.Y McGraw-Hill Book Co., 1981, pp.33-38.

19. BALL, R. \& BROWN, P. "An Empirical Evaluation of ACcounting Numbers". Journal of Accounting Research, outono de 1968, pp. 159-178.

20. FAMA E. F.; FISCHER, L.; JENSEN, M. \& ROLL, $R$. "The Adjustment of Stock Prices to New Information". International Economic Review, fevereiro, 1969, pp. 1-21. 
ou porque a empresa em questão não as entregou efetivamente. Por exemplo, no período de janeiro a abril de 1989, das 60 empresas originalmente escolhidas, quatro não o fizeram, ou não pudemos constatar essa entrega no BDI (Hering, Polipropileno, Prometal e Samitri).

Além disso, as séries diárias de lucratividade publicadas pela Bolsa de Valores de São Paulo não costumam ser ajustadas por dividendos, bonificações e subscrições, o que torna necessário reunir também essas informações, para que se calcule a lucratividade efetivamente obtida pelo investidor.

Por fim, a obtenção de cópias de demonstrações financeiras junto à Bolsa de Valores de São Paulo ou à Comissão de Valores Mobiliários é um processo burocratizado, a não ser, no caso da Bolsa de Valores, que se esteja vinculado a uma das entidades associadas (corretora de valores). Para resolver esse problema, conseguimos acesso ao arquivo de demonstrações financeiras do Instituto Brasileiro de Mercado de Capitais (IBMEC). Mesmo assim, porém, algumas empresas foram excluídas da amostra porque as demonstrações financeiras não permitiam o cálculo de todos os índices necessários, por falha de apresentação de responsabilidade da própria empresa.

\section{c) Fontes de dados coletados}

Portanto, os dados foram obtidos junto às seguintes instituições e publicações:

1. Bolsa de Valores de São Paulo, Boletim Diário de Informações (inclusive "Quadro de Evolução do Capital Social das Empresas") e Informe Técnico;

2. Instituto Brasileiro de Mercado de Capitais, SABE - Sistema de Análise de Balanços Empresariais para microcomputadores;

3. Associação Nacional das Distribuidoras do Mercado, Aberto, Carta Andima.

d) Periodo de estudo e empresas (ativos) componentes da amostra

Nossa preocupação foi com a divulgação do valor patrimonial da ação quando da entrega das demonstrações financeiras relativas ao exercício de 1988 , portanto, no início de 1989.

Com esses dados, queríamos medir a variação relativa do valor patrimonial da ação entre o balanço da empresa no final de 1987 e o balanço ao fim de 1988 .

Conseqüentemente, a coleta de datas de entrega de demonstrações financeiras, bem como séries de lucratividades diárias em datas próximas às do evento se concentrou no período de 2 de janeiro a 28 de abril de 1989 .
Para a estimação de betas a serem usados no cálculo de resíduos em relação ao capital asset pricing model, foram obtidas séries de lucratividades mensais no período de janeiro de 1986 a dezembro de 1988.

Quanto à taxa representativa de uma aplicação sem risco, levantamos uma série de taxas médias mensais do mercado secundário de Letras Financeiras do Tesouro, que foram convertidas, a seguir, em seus equivalentes diários.

Como já foi dito, partimos de uma lista original de 60 empresas com ações dentre as mais negociadas na Bolsa de Valores de São Paulo. Por diversos motivos, houve exclusões que deixaram ao final uma amostra de 43 ativos (para cada empresa, uma certa classe de ações). A lista completa dos códigos das ações e das denominações dessas empresas pode ser encontrada no Anexo 1 deste trabalho.

e) Variáveis explicativas de resíduos acumulados

Para explicar as diferenças contemporâneas entre resíduos acumulados nas respostas do mercado às notícias referentes a empresas distintas, foi preciso analisar e estimular um modelo de regressão linear múltipla no qual foram incluídas as seguintes variáveis explicativas:

- VPA = variação relativa do valor patrimonial da ação, entre o final de 1987 e o final de 1988. Obviamente, essa é a variável de maior interesse no presente estudo e, segundo a utilização que supomos ser feita pelo mercado, previa-se um coeficiente positivo para a variável.

Um coeficiente positivo e significativamente diferente de zero indicaria que essa variável possui conteúdo informacional importante. Mas, em vista da discussão do item "O Conteúdo Informacional do Valor Patrimonial" deste trabalho, esse resultado deve ser interpretado como evidência de "ilusão financeira" ou irracionalidade em nosso mercado, a não ser que a variável esteja fortemente correlacionada com outra que afete os fluxos de caixa para a empresa e os seus acionistas (ou seja, tenha significado econômico).

- LPA = variação relativa do lucro por ação, entre final de 1987 e final de 1988. Essa variável foi incluída para refletir duas considerações: a) o mercado pode estar mais interessado nela do que na variação do valor patrimonial, de modo que os resíduos acumulados observados seriam melhor explicados pela informação sobre LPA, uma variável sobre a qual estaria havendo divulgação concomitante, e b) VPA e LPA podem estar positivamente correlacionadas de uma maneira muito intensa, de modo que interesse descobrir o 
conteúdo informacional marginal de cada uma.

O sinal esperado de seu coeficiente era positivo, pois estaria diretamente associada à possibilidade de maiores fluxos de caixa futuros para os investidores.

- FAT = crescimento real do faturamento entre o exercício de 1987 e o exercício de 1988. Procedemos à inclusão dessa variável pelos mesmos motivos apontados acima para LPA. O sinal esperado de seu coeficiente era positivo.

- DEBTEQ = variação relativa do quociente entre exigível total e não-exigivel, entre as mesmas datas, como reflexo de alterações de risco financeiro. $O$ coeficiente dessa variável deve ter sinal negativo.

- COBERT = variação relativa do índice de cobertura de despesas financeiras (resultado operacional antes de despesas financeiras, dividido por despesas financeiras). Tal como DEBTEQ uma medida de alterações de risco financeiro. Quanto maior o índice, menor o risco financeiro, portanto, o sinal esperado do coeficiente dessa variável é positivo.

Para todas essas variáveis, é importante notar que o mais correto teria sido calcular as diferenças entre o valor observado e o valor esperado pelo mercado quando da data de divulgação.
Entretanto, isso exigiria que se construísse um modelo de formação de expectativas para cada variável, o que em si já seria objeto de vários outros estudos. Em contrapartida, porém, como a análise é feita com base numa cross section, as diferenças entre as empresas já são levadas em conta, e o problema aqui apontado é bastante suavizado, desde que se suponha que o modelo de expectativas para cada variável seja o mesmo para todas as empresas.

\section{Medidas obtidas}

a) Cálculo de betas

Já que $\beta_{j}=\operatorname{cov}\left(R_{j t}, R_{m t}\right) / v a r\left(R_{m t}\right)$, e esta é a definição do coeficiente de inclinação da reta de regressão linear simples, ou seja, $\beta_{\mathfrak{j}}$ no modelo

$$
R_{j t}=a_{j}+\beta_{j} R_{m t}+e_{j t}
$$

o coeficiente beta, para cada ativo $j$, foi estimado através dos valores obtidos para $\beta_{j}$ na equação acima. Com as hipóteses usuais do modelo linear geral para duas variáveis, usamos o método dos mínimos quadrados ordinários.

Em alguns casos, conforme é indicado pelos resultados apresentados na tabela 1 , o teste Durbin-Watson apontou correlação serial positiva significante de primeira ordem entre os resíduos. Assim, nesses casos, apelamos para a

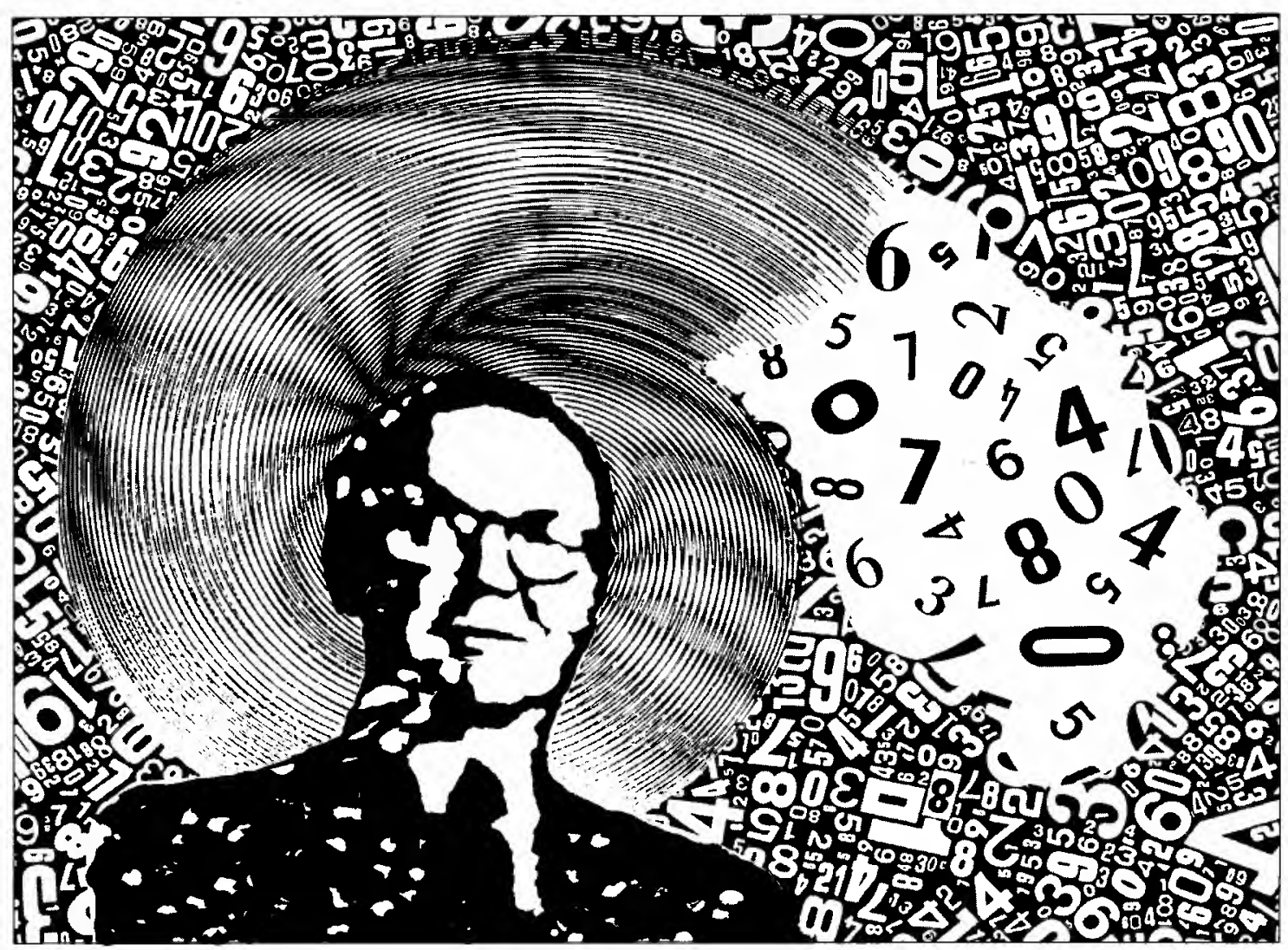


Tabela 1: Resultados da análise de regressão linear simples entre retornos de cada ação e retomos do índice Bovespa, dados mensais de janeiro de 1986 a dezembro de 1988

\begin{tabular}{|c|c|c|c|c|c|}
\hline Ação & Intercepto & Beta estimado & $\mathbf{R 2}$ & $\mathbf{F}$ & DW \\
\hline AVI2 & -0.4741 & 0.8921 & 0.7119 & 84.026 & 1.7654 \\
\hline ALP4 & 1.5055 & 0.9790 & 0.6580 & 65.406 & 2.2326 \\
\hline BEL2 & 1.7880 & 1.0395 & 0.7695 & 113.490 & 1.7439 \\
\hline $\mathrm{BRH} 2$ & 7.1589 & 0.7756 & 0.5092 & 35.276 & 1.7107 \\
\hline $\mathrm{CIQ2}$ & 4.3278 & 0.6931 & 0.3456 & 17.971 & 2.0726 \\
\hline CBV2 & -4.3712 & 0.9016 & 0.4441 & 271.664 & 1.6869 \\
\hline CEV4 & 3.4616 & 0.9966 & 0.4883 & 32.448 & 1.6834 \\
\hline ICP4 & 3.9732 & 0.8794 & 0.5217 & 37.089 & 2.5870 \\
\hline FAP2 & 2.0807 & 1.2934 & 0.7710 & 114.450 & 2.0429 \\
\hline CNF2 & -0.8106 & 1.1230 & 0.6815 & 72.755 & 2.3064 \\
\hline CPN7 & 5.0639 & 1.2894 & 0.7386 & 96.074 & 1.9576 \\
\hline $\operatorname{csS} 2$ & 9.6945 & 0.4831 & 0.1753 & 7.227 & 1.7323 \\
\hline EST2 & 0.6974 & 0.9274 & 0.6143 & 54.157 & 1.2247 \\
\hline FNV6 & -5.3574 & 2.0811 & 0.5263 & 37.775 & 2.2490 \\
\hline FES2 & 1.2625 & 1.1445 & 0.7532 & 103.785 & 1.8438 \\
\hline FER2 & 4.5984 & 0.7514 & 0.2248 & 9.857 & 2.0733 \\
\hline $\mathrm{CPF2}$ & -0.2737 & 1.1737 & 0.7500 & 102.006 & 2.1526 \\
\hline FRI4 & 2.4015 & 0.9862 & 0.5138 & 35.928 & 2.2334 \\
\hline PTI2 & 0.5943 & 1.3040 & 0.6454 & 61.871 & 2.4643 \\
\hline $\mathrm{KLA2}$ & 4.8506 & 0.8868 & 0.6663 & 67.891 & 1.5770 \\
\hline POM2 & 2.8264 & 1.4281 & 0.5775 & 46.478 & 2.0923 \\
\hline MEN8 & -7.3531 & 1.4185 & 0.6349 & 59.114 & 2.3102 \\
\hline LEV2 & 0.6473 & 0.9357 & 0.7109 & 83.586 & 1.9424 \\
\hline MSA1 & 2.6357 & 0.7841 & 0.7245 & 89.401 & 2.0961 \\
\hline OLV2 & -1.1771 & 1.3646 & 0.6598 & 65.927 & 1.6036 \\
\hline PRB2 & -3.0003 & 1.0557 & 0.6018 & 51.385 & 1.7623 \\
\hline PMA2 & 0.4381 & 1.0715 & 0.7793 & 120.044 & 1.7768 \\
\hline PDG2 & 2.4017 & 0.9459 & 0.3730 & 20.228 & 2.1761 \\
\hline PRS2 & 0.3209 & 1.3799 & 0.5840 & 47.739 & 2.1013 \\
\hline PET2 & 0.5270 & 1.0347 & 0.7815 & 121.586 & 1.5235 \\
\hline PIR1 & -0.7416 & 1.2606 & 0.6803 & 72.352 & 1.8986 \\
\hline $\mathrm{SCO4}$ & -1.5280 & 1.3355 & 0.4956 & 33.411 & 2.2921 \\
\hline SHA2 & -8.6041 & 1.0835 & 0.5594 & 43.174 & 1.4131 \\
\hline SID2 & -5.7599 & 0.8686 & 0.3807 & 20.900 & 1.3799 \\
\hline $\mathrm{RIO2}$ & 0.7190 & 1.0250 & 0.6682 & 68.463 & 2.0413 \\
\hline CRU1 & 5.3390 & 0.6425 & 0.4625 & 29.259 & 2.3786 \\
\hline SUZ2 & 2.6531 & 0.9763 & 0.7611 & 108.306 & 1.5954 \\
\hline TRB2 & 1.9383 & 0.6956 & 0.4136 & 23.982 & 1.9589 \\
\hline TUP4 & 9.6649 & 0.8746 & 0.3751 & 20.408 & 2.2385 \\
\hline VAL2 & 0.6712 & 1.0986 & 0.7095 & 83.025 & 2.3508 \\
\hline VAG2 & 0.9418 & 0.7070 & 0.5843 & 47.794 & 2.1080 \\
\hline VSM1 & 3.0146 & 0.8612 & 0.7339 & 93.782 & 1.6972 \\
\hline WHM1 & 1.8238 & 1.0579 & 0.8064 & 141.578 & 1.2958 \\
\hline
\end{tabular}


correção Cochrane-Orcult para autocorrelação e 08 coeficientes foram novamente estimados ${ }^{21}$.

Os coeficientes beta também foram estimados com dados mensais deflacionados pelo Indice Geral de Preços (IGP-DI) da Fundação Getúlio Vargas. Embora os coeficientes obtidos năo scjam idênticos, as diferenças são virtualmente imperceptíveis, às vezes não sendo notadas à quarta casa decimal.

Por meio do teste Durbin-Watson, foi observado que em alguns casos havia autocorrelação dos resíduos. Embora isso não leve a estimadores vicsados, para esses casos utifizamos o procedimento de correção Cochrane-Orcutt, já mencionado, e que levou aos resultados que podem ser vistos na tabela 2 .

\section{b) Residuos midios acumulados}

A partir dos valores estimados para os $\mathrm{CO}^{-}$ eficientes beta de cada ação, das taxas diárias de juros das LFTS e das lucratividades diárias do indice Bovespa, foram calculados os residuos diários para cada uma das ações da amostra, de 2 de janeiro a 28 de abril de 1989

Como já foí explicado, os resíduos consistem em diferenças entre as lucratividades diárias de cada ação (variação relativa entre preços de fechamento de dois pregões consenitivos) e a hrontividade esperada segundo o capilal asset pricing model.

Para fins de análise, concentramo-nos no período entre 30 pregões antes do evento e 5 pregóes após a data em que julgamos estarem fisponíveis as demonstrações financeiras.

A seguir, os residuos de todas as ações, em ada uma das datas, foram somados e dividiCos pelo númor de observações naquela data, efetivamente montando-se uma carteira de residuos, com pesos iguais

Por fim, os residuos da carteira foram acumolados a partir de $t=-30$ (30 pregoes antes do evento)

c) Modelo de rovessão linear múltipla

Para avaliar conteúdo informacional da variação do valor patrimonial, nos propusemos a estimar seguinte modelo:

$$
\begin{aligned}
\text { CUM }_{j}= & a+b 1 \operatorname{VPA}_{j}+\text { b2 } \text { FAT }_{j}+\text { b3 LPA }_{j}+ \\
& + \text { b4 COBLRT } \\
& + \text { b5 DEBTEQ }_{j},
\end{aligned}
$$

onde $j=1,2 \ldots, 43$ empresas.

\section{RESULTADOS}

1. Resíduos diários e resíduos acumulados: o comportamento da amostra como um todo

De acordo com o exposto no item anterior deste trabalho, foram calculados os retornos extraordinários (resíduos) médios da carteira formada pelas ações incluídas na amostra, desde 30 pregões antes da data do evento, até 5 pregões após essa mesma data. A seguir, os resíduos foram acumulados dentro desse mesmo intervalo.

As figuras 1 e 2 apresentam uma visão gráfica do resultado desse processo. Na figura 1 , referente aos resíduos médios, é assinalada a faixa compreendida entre dois desviospadrão em relação ao valor esperado (que é zero, como vimos anteriormente). Como se observa, o resíduo da carteira na data do evento é igual a $-1.2766 \%$. Como o desviopadrão é igual a $0,7086 \%$, a estatística $Z$, para a hipótese nula de resíduo igual a zero, é 1,8016 , o que indica que o resultado, na data do evento, não é diferente de zero ao nível de significância de $5 \%$. A $10 \%$ de significância, a hipótese nula já seria rejeitada, entretanto.

Outras observações merecem ser feitas sobre a Figura 1:

a) a partir de 10 pregões anteriores à data do evento, todos os resíduos são negativos com exceção em $\mathrm{t}=-2$, e por muito pouco; isso pode indicar antecipação ou "vazamento" da informação, ou ainda, sua divulgação através de outro meio;

b) para a carteira, ou seja, a média das 43 empresas da amostra, a reação do mercado é negativa, indicando que as demonstrações financeiras, em seu conjunto, apontavam para resultados e posições econômico-financeiras inferiores às esperadas até então.

A figura 2, por sua vez, que apresenta os resíduos acumulados a partir de 30 pregões antes da data do evento, mostra uma queda

Tabela 2: Resultados para algumas ações, após correção Cochrane-Orcutt por autocorrelação dos resíduos

\begin{tabular}{|c|c|c|c|c|c|}
\hline Ação & Intercepto & Beta estimado & R2 & F & DW \\
\hline EST2 & -1.4973 & 0.9861 & 0.6829 & 73.215 & 2.2591 \\
\hline SID2 & -5.5245 & 0.8393 & 0.4209 & 24.709 & 1.6126 \\
\hline WHM1 & 1.1346 & 1.0619 & 0.8219 & 156.899 & 1.8096 \\
\hline
\end{tabular}

21. Quanto 20 rocedimento Cochrane-Orcutt ver JOHN STON d. Economerric Methods 3a ed. New Yosk, N.Y, MC Graw-Hill Bock Co., 1984 p. $323-325$ 
Figura 1: Retornos extraordinários diários para a carteira formada com as 43 empresas da amostra, em porcentagem, de 30 pregões antes da data do evento até 5 pregões após essa data

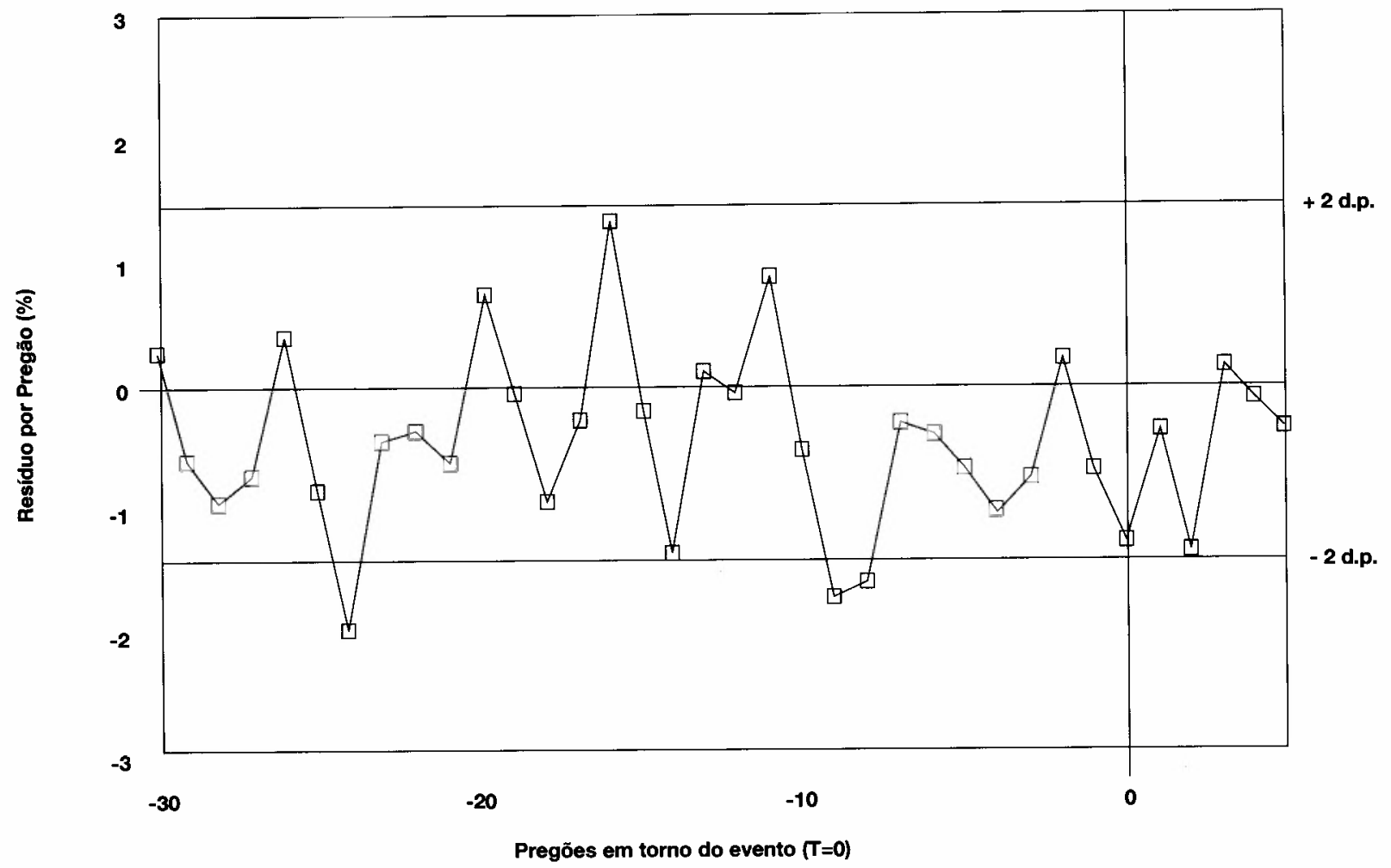

Figura 2: Retornos extraordinários acumulados para a carteira formada com as 43 empresas da amostra, em porcentagem, de 30 pregões antes da data do evento até 5 pregões após essa data

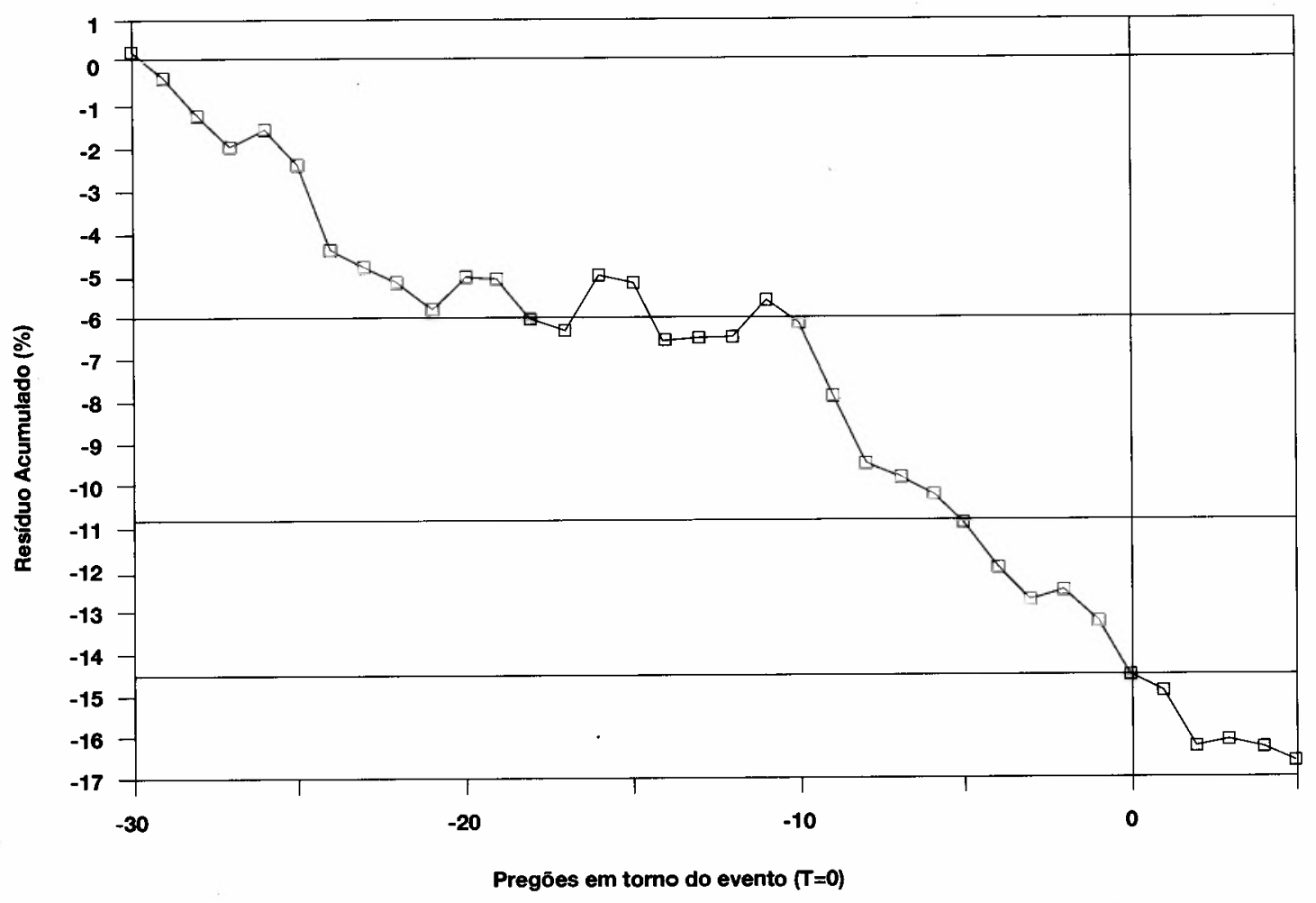




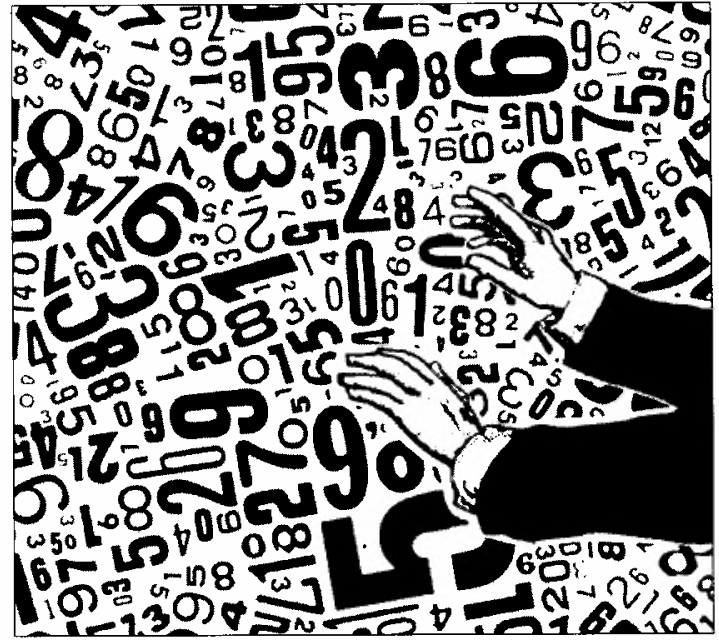

praticamente ininterrupta do valor da carteira, principalmente a contar de 10 dias antes do evento. A carteira se desvalorizou aproximadamente $14,5 \%$, depois de descontados o comportamento do mercado e a taxa de retorno do ativo sem risco, em pouco mais de um mês. Além disso, destaque-se que de 10 pregões antes do evento, até a data do evento, a queda foi de $8,8326 \%$. Levando em conta que esse período compreende 11 dias de operação do mercado, e que o desvio-padrão do resíduo diário é igual a $0,7086 \%$, obtém-se uma estatística " $\mathrm{t}$ " de Student de 3,7583, significativamente diferente de zero.

Portanto, a divulgação das demonstrações financeiras pode, em seu conjunto, ser considerada um evento com conteúdo informacional significativo, mas que parece sofrer alguma antecipação pelo mercado. Por fim, para esse conjunto de empresas, as notícias foram consideradas indicativas de uma situação real inferior à esperada.

2. Análise da resposta dos preços dos componentes da carteira a variações do valor patrimonial

Como este trabalho se propôs verificar até que ponto o valor patrimonial da ação possui conteúdo informacional, o passo seguinte consistiu em utilizar um modelo de regressão linear múltipla para estabelecer a correlação entre retornos extraordinários, por empresa, e as variações do valor patrimonial da ação, também por empresa.

Porém, como já tivemos oportunidade de explicar, a divulgação de demonstrações financeiras não comunica apenas variações do valor patrimonial, podendo os retornos extraordinários, que medem a resposta do mercado, estar associados a novos valores de lucro por ação, faturamento, e outros indicadores, como os de endividamento e risco financeiro.
Assim, tratamos de estimar o modelo exposto no item "Metodologia" deste trabalho, no que efetivamente é uma análise tipo crosssection.

Inicialmente, examinada a matriz de coeficientes de correlação entre as variáveis, descobriram-se elevados coeficientes para os pares VPA e LPA $(0,4956)$ e FAT e DEBTEQ $(0,8165)$. Obviamente, essas correlações entre variáveis explicativas são possíveis fontes de multicolinearidade, a qual torna os estimadores nãoeficientes, com a possível não-rejeição de uma hipótese nula de que os coeficientes de variáveis afetadas fossem iguais a zero, quando na verdade eles são diferentes de zero.

Portanto, a estimação do modelo de regressão foi feita com certos cuidados em função da possível multicolinearidade.

Os melhores resultados, em termos de modelo de regressão, foram obtidos com resíduos acumulados de $t=-5$ até $t=0$, e esses resultados são os que aqui relatamos.

O melhor modelo de regressão obtido foi:

$\mathrm{CUM}_{\mathrm{j}}=-12.6553+0.6260 \mathrm{VPA}_{\mathrm{j}}+8.7343 \mathrm{FAT}_{\mathrm{j}}-0.1727 \mathrm{LPA}_{\mathrm{j}}$

$$
\begin{array}{llll}
(3.2580) \quad(1.6719) \quad(2.4320) \quad(1.6919)
\end{array}
$$

$\mathrm{R}^{2}=0,1852 \quad \mathrm{~F}=2.9545 \quad \mathrm{~N}=43$ observações

Nessa equação, os valores entre parênteses, abaixo dos coeficientes estimados, são estatísticas " $\mathrm{t}$ " de Student. Como o número de graus de liberdade é igual a 39, pode-se notar que, a $5 \%$ de significância, apenas os coeficientes das variáveis FAT e LPA são significativamente diferentes de zero. É importante lembrar que o " $\mathrm{t}$ " crítico para esse nível de significância, é aproximadamente igual a 1,684, já que se trata de testes monocaudais.

Como um todo, o modelo deve ser considerado satisfatório, já que o valor crítico de $\mathrm{F}$ é aproximadamente 2,61 , para o mesmo nível de significância de $5 \%$.

Quanto aos resultados específicos, três coisas chamam a atenção:

a) conforme os resultados, a variação do valor patrimonial da ação não possui conteúdo informacional marginal significante;

b) a variável LPA apresenta um coeficiente significativamente negativo, ao contrário do esperado. Se não possuísse conteúdo informacional além do contido em VPA e FAT, seu coeficiente não seria significativamente diferente de zero. Entretanto,não só ele o é, como a correlação entre LPA e CUM é negativa (-0.2732). Só nos resta conjecturar, portanto, que um elevado LPA é uma má notícia, talvez porque venha a obrigar a empresa a pagamentos de dividendos mais elevados, e o 
mercado prefira rendimentos sob a forma de ganhos de capital. Por fim, talvez o que importe seja o fluxo de caixa por ação, e não o lucro, mas isso não levaria necessariamente a um coeficiente negativo para a variável LPA.

c) além da variação do lucro por ação, o crescimento do faturamento aparece como indicador importante de desempenho da empresa, em termos da intensidade da reação do mercado.

Quando as variáveis COBERT e DEBTEQ foram incluídas, os sinais obtidos para seus coeficientes foram tal como esperados, ou seja, positivo para a primeira variável, e negativo para a segunda. Entretanto, as estatísticas " $\mathrm{t}$ " calculadas foram apenas 0,7215 e 0,0402, respectivamente, e a estatística $\mathrm{F}$ do modelo caiu para 1,8117 (contra um valor crítico de 2,36).

\section{CONCLUSÕES E COMENTÁRIOS FINAIS}

Costuma-se atribuir a Janus - o deus romano de duas faces - a proteção dos administradores. A tradição nos ensina que as duas faces do deus representavam a sua sabedoria: pelo conhecimento do passado, ele antecipava o futuro. As previsões do futuro consistem na própria base da atividade profissional dos administradores em geral e dos analistas financeiros em particular, e tentar fugir do arriscado exercício da previsão não enriquecerá essas profissões. Os talentos requeridos para a área de Finanças necessariamente incluem a sensibilidade e a técnica da análise do passado para fundamentar a intuição e a técnica da previsão. Sob esse enfoque, a comparação entre cotações de mercado e valores patrimoniais contábeis das ações representa uma fuga do raciocínio projetante e uma super-simplificação grosseira da teoria do valor.

É certo que em Finanças a teoria avançou mais rapidamente que a tecnologia dos instrumentos de cálculo e que, durante décadas, essas idéias ficaram restritas ao âmbito acadêmico. Mas, a década de 80 colocou à nossa disposição instrumentos de cálculo adequados e acessíveis. Por outro lado, a Estatística e a Econometria (áreas do conhecimento humano em que a previsão é o núcleo de interesse) aos poucos também estão sendo banalizadas na medida em que a informática avança. Certamente, as técnicas e os modelos, antes restritos ao meio acadêmico, vão chegando às mesas dos executivos. É preciso reconhecer a mudança que está em marcha e abandonar antigos mitos que ainda povoam o nosso espírito. Sob esse aspecto, a atitude do governo é fundamental, principalmente, se ele estiver empenhado com sinceridade na modernização da economia. Mas, tanto no Legislativo como no Executivo, o valor patri- monial contábil ainda serve como elemento de referência, quando se trata de avaliações.

A legislação das sociedades por ações, em vários pontos, dá apoio à utilização do valor patrimonial contábil em questões com real significado econômico. Se, de um lado, essa posição revela conhecimento inadequado da teoria financeira moderna, de outro lado sanciona e fortalece o uso do valor patrimonial para fins de tomada de decisão com real significado econômico: o valor patrimonial contábil não teria significado econômico, em si mesmo, como prevê a teoria, mas ao estar correlacionado com decisões com real significado, por fiat de autoridades reguladoras do mercado obrigaria os investidores prudentes a levá-lo em conta. A tributação de ganhos de capital também é questionável porque, por recair sobre a variação do valor, na verdade, tributa projeções de rendas futuras e/ ou redução da incerteza dessas projeções, constituindo em mais um relevante "ruído" no processo de formação dos preços nos mercados secundários de valores mobiliários.

Após termos demonstrado, no início deste trabalho, a irrelevância do valor patrimonial da ação como medida de valor para decisões de investimento com real significado econômico, procedemos a uma verificação empírica de sua importância em nosso mercado. Isso foi feito com o recurso à montagem de um event study, envolvendo a divulgação da entrega de demonstrações financeiras à Bolsa de Valores de São Paulo.

Os retornos extraordinários, por sua vez, foram medidos com o uso do capital asset pricing model, e o comportamento desses retornos mostrou, inicialmente, que a divulgação dos resultados anuais das empresas da amostra, referentes ao exercício de 1988, se constituiu em informação desfavorável, do ponto de vista do mercado. Além disso, a própria divulgação, em termos do evento definido neste trabalho, foi objeto de alguma antecipação, possivelmente com a divulgação por meio de outro veículo.

Entretanto, como a divulgação de demonstrações financeiras também fornece dados sobre outros indicadores de potencial interesse para o mercado (por exemplo, lucro por ação, crescimento do faturamento, alterações do nível de risco financeiro), tivemos o cuidado de medir o impacto marginal de variações do valor patrimonial, ou seja, descontando explicitamente as variações desses outros indicadores possivelmente importantes.

Os resultados obtidos mostraram duas coisas. Em primeiro lugar, e diretamente, que o valor patrimonial efetivamente não possui conteúdo informacional significativo em nosso mercado. Em segundo lugar, e como con- 
seqüência do primeiro resultado, que a defesa desse indicador irrelevante de valor, no sentido econômico, não é sequer justificada pelos dados a respeito do comportamento de nosso mercado. Esse resultado é tranquilizador - porque mostra, efetivamente, a não utilização prática pelos participantes do mercado de um indicador baseado em "ilusão financeira".

Acreditamos que este trabalho, por ser talvez a primeira tentativa de event study realizada no Brasil, abra caminho para vários outros estudos que permitam um melhor conhecimento, genuinamente técnico, da realidade de nosso mercado. As deficiências do trabalho, que provavelmente são inúmeras, devem servir de incentivo para que outros pesquisadores, ao criticá-las, ampliem esse conhecimento técnico tão necessário.

Em particular, cabe uma pesquisa específica sobre o "mistério" do resultado que obtivemos para as variações do lucro por ação. As regressões analisadas indicaram que elas possuem conteúdo informacional, mas que a sua associação com variações de preço é na direção contrária do que normalmente se esperaria.

Por fim, a metodologia de event study pressupõe uma escolha adequada quanto à data real de ocorrência do evento. A antecipação de informações, por nós detectada, talvez indique a necessidade de estudos e discussões, com maior profundidade, não só do processo de divulgação de informações sobre ativos, em nosso mercado, como da importância atribuída pelos investidores e analistas a cada um dos veículos disponíveis de divulgação.

Toda essa discussão auxiliará não apenas na conduta dos investidores e analistas propriamente ditos, como contribuirá para o aperfeiçoamento futuro da legislação e regulamentação do mercado de capitais. $\square$

Anexo 1: Empresas e ativos componentes da amostra analisada

\begin{tabular}{|c|l|l|l|}
\hline Código da ação & Nome da empresa e classe da ação & Código da ação & Nome da empresa e classe cle ação \\
\hline AVI2 & AÇOS VILLARES PP & LEV2 & METAL LEVE PP \\
\hline ALP4 & ALPARGATAS PN & MSA1 & MOINHO SANTISTA OP \\
\hline BEL2 & BELGO-MINEIRA PP & OLV2 & OLVEBRA PP \\
\hline BRH2 & BRAHMA PP & PRB2 & PARAIBUNA PP \\
\hline CIQ2 & CACIQUE PP & PMA2 & PARANAPANEMA PP \\
\hline CBV2 & CBV INDS. MECÂNICAS PP & PDG2 & PERDIGÃO PP \\
\hline CEV4 & CEVAL PN & PRS2 & PERSICO PP \\
\hline ICP4 & CIMENTO ITAU PN & PET2 & PETROBRÁS PP \\
\hline FAP2 & COFAP PP & PIR1 & PIRELLI OP \\
\hline CNF2 & CONFAB PP & SCO4 & SADIA CONCÓRDIA PN \\
\hline CPN7 & COPENE PPA & SHARP PP \\
\hline CSS2 & CRUZEIRO DO SUL PP & SHA2 & SID INFORMÁTICA PP \\
\hline EST2 & ESTRELA PP & SIDERÚRGICA RIOGRANDENSEPP \\
\hline FNV6 & FNV PPA & RIO2 & SOUZA CRUZ OP \\
\hline FES2 & FERBASA PP & CRU1 \\
\hline FER2 & FERRO BRASILEIRO PP & SUZ2 & SUZANO PP \\
\hline CPF2 & FERRO LIGAS PP & TRB2 & TRANSBRASIL PP \\
\hline FRI4 & FRIGOBRÁS PN & TUPY PN \\
\hline PTI2 & PETRÓLEO IPIRANGA PP & TUP4 & VALE DO RIO DOCE PP \\
\hline KLA2 & KLABIN PP & VAL2 & VARIG PP \\
\hline POM2 & MARCOPOLO PP & VAG2 & WHITERARIA SANTA MARINA OP \\
\hline MEN8 & MENDES JUNIOR PPB & WHM1 & \\
\hline
\end{tabular}

